\title{
O espaço comercial e a satisfação dos utili- zadores: uso de realidade virtual imersiva para simulação de alternativas de projeto
}

The commercial space and the satisfaction of its users: use of immersive virtual reality to simulate project alternatives

Ricardo Ribeiro*, Sara Eloy**, Pedro Esteves***

*Instituto Universitário de Lisboa (ISCTE-IUL)

${ }^{* *}$ Instituto Universitário de Lisboa (ISCTE-IUL), ISTAR-IUL

***Instituto Universitário de Lisboa (ISCTE-IUL), AUDAX

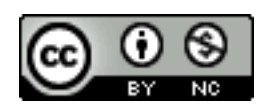

Recebido: $14 / 04 / 2020$ Aceito: 04/08/2020

https://doi.org/10.37916/arq.urb.v28i.421

usjt • arq.urb • número 28 | maio-agosto de 2020

\section{Resumo}

Em arquitetura o diálogo entre o arquiteto e o cliente e os utilizadores finais do espaço projetado é de extrema importância para a concretização de um projeto que responda às expetativas do utilizador. Desse diálogo deve fazer parte uma participação ativa do utilizador final no processo de conceção do projeto que vai aumentar o seu envolvimento com as propostas que se pretendem executar garantindo assim uma maior satisfação deste com o espaço. O presente estudo foi realizado em parceria com um cliente real, a Galp, e tem como foque a elaboração de um projeto de alteração de uma das suas lojas de conveniência, introduzindo novos conceitos para o espaço comercial. Para além da proposta de alterações pretendia-se consultar os utilizadores finais do espaço e avaliar a sua satisfação perante as propostas apresentadas. Para tal optou-se por realizar testes de satisfação com recurso à Realidade Virtual Imersiva (RVI) enquanto método de simulação do espaço. A RVI foi utilizada em testes com os utilizadores finais e permitiu concluir que os inquiridos consideram que as propostas apresentadas valorizam o espaço comercial e a mobilidade dentro da loja. Conclui-se também que o uso de RVI ajuda a um bom entendimento do espaço.

Palavras-chave: Arquitetura, ambientes virtuais, espaço comercial.

\section{Abstract}

In architecture the dialogue between the architect and the client and end users is of extreme importance in order to respond to the expectations of the users. This dialogue should include an active participation of the end user in the design process. Such an involvement increases the users' engagement with the proposals guaranteeing a greater satisfaction of them with the final built space. The present study was carried out in partnership with a real customer, Galp, and focuses on the design of a transformation to one of Galps' convenience stores by introducing new concepts for the commercial space. In addition to the proposed changes, it was intended to consult the clients (end users of the store) and evaluate their satisfaction with the proposals presented. For this, it was decided to perform satisfaction tests using Immersive Virtual Reality (IVR) as a space simulation method. The IVR was used in tests with the end users and allowed to conclude that users consider that the presented proposals value the commercial space and the mobility within the store. It is also concluded that the use of IVR helps a good understanding of space for lay-persons.

Keywords: Architecture, virtual environments, commercial space. 


\section{Introdução}

A perceção do espaço arquitetónico pelos seus utilizadores finais e pelos clientes é um aspeto que tem sido alvo de discussão e investigação no sentido de garantir que o diálogo entre estes e o arquiteto seja claro e o mais possível omisso de equívocos. Neste trabalho utilizamos a expressão utilizador para referir quem de facto utiliza o espaço construído e cliente para referir quem encomenda o trabalho ao arquiteto (que pode ou não ser também utilizador).

É complexo o entendimento e leitura de plantas, cortes e alçados de projeto para quem não tem qualquer contato ou formação na área da arquitetura. Neste contexto, o arquiteto muitas vezes encontra uma tarefa penosa no processo de discussão com os clientes e no momento de divulgação. É assim fulcral melhorar os processos de comunicação durante as fases de projeto de arquitetura de modo a obter bons resultados em termos de perceção do projeto e consequentemente uma aceitação plena da obra final. Uma clara perceção do espaço por parte dos utilizadores permite ao ar- quiteto avaliar o comportamento que os utilizadores finais vão adotar aquando utilizadores do espaço construído. Um correto entendimento do espaço projetado por parte dos futuros utilizadores permite ainda ao arquiteto obter dados que o podem auxiliar na escolha do caminho a seguir ou assegurar a validade dos argumentos e soluções propostas no projeto.

As ferramentas de simulação do espaço arquitetónico que utilizam meios de visualização mais próximos do processo natural de ver com o olhar humano são potenciadores de uma melhor perceção do espaço projetado. Entre estas, a Realidade Virtual Imersiva (RVI) permite uma visualização completa do espaço, à escala real, dando ao utilizador a sensação de que se encontra num espaço real. Assim o uso da RVI em discussões de projeto entre arquiteto e utilizador permite analisar a reação do utilizador à proposta e antever como este usará o ambiente real. As simulações da realidade através de ambientes virtuais têm vindo, cada vez mais, a ser utilizadas nas várias fases de projeto quer em escolas de arquitetura quer em contexto de projeto real. 
A RVI tem vindo a ganhar mais apoiantes pela facilidade de uso, nomeadamente a facilidade com que se modelam e modificam os modelos tridimensionais, e pelo facto de ser possível ter a noção de escala natural no edifício, facilitando, deste modo, o diálogo entre ambas as partes envolvidas no processo de criação.

No presente trabalho, com recurso à RVI, é realizado um estudo académico sobre o espaço arquitetónico comercial e a perceção e satisfação dos utilizadores perante alterações propostas a este. Pretende-se avaliar a validade de propostas de alterações do espaço através da análise do impacto que as mesmas têm nos utilizadores. Pretende-se também avaliar a eficácia do uso de RVI em contexto de comunicação entre arquiteto e utilizador. Neste âmbito realizou-se uma parceria com a Galp no contexto das lojas de conveniência Tangerina, de modo a poder desenvolver novos conceitos de lojas e testá-los junto dos utilizadores finais. O trabaIho debruça-se sobre as lojas de conveniência que constituem pequenas lojas situadas nos pontos de abastecimento de combustível da Galp e nas quais se vendem diversos tipos de produtos.

O presente trabalho é dividido em cinco partes, primeiramente são apresentadas as perguntas de investigação e os objetivos do trabalho, de seguida é apresentado o estado da arte sobre os temas utilizados como base do trabalho, assim como alguns casos de estudo realizados no âmbito da realidade virtual, da arquitetura e do marketing. Na terceira parte é apresentado todo o projeto realizado com vista a resolver os problemas identificados na loja bem como a realização dos elementos necessários para concretizar uma experiência com utilizadores finais em RVI. Na quarta parte é apresentada a experiência realizada e por último são apresentadas conclusões sobre o trabalho feito e também uma reflexão sobre o mesmo.

\section{Pergunta de investigação e objetivos}

O presente trabalho coloca algumas questões fulcrais ao nível da arquitetura, do espaço comercial, do marketing e da aproximação ao cliente e ao utilizador e a sua reação perante o espaço projetado. As questões de investigação que suscitaram este trabalho são:

- Como garantir que os clientes de um projeto de arquitetura, leigos em representação gráfica, tenham uma correta perceção do espaço arquitetónico projetado?

- Qual o papel da RVI na aproximação da arquitetura ao cliente e aos utilizadores finais do espaço?

- A visualização de um projeto de arquitetura através de mecanismos de RVI, nomeadamente com Head Mounted Display (HDM,) permite que os clientes de arquitetura tenham uma visão mais clara do projeto? 
No seguimento destas questões, os objetivos que se pretende alcançar são os seguintes:

1. Avaliar se o uso de RVI é útil na perceção do espaço arquitetónico antes da sua construção;

2. Avaliar junto de utilizadores finais a sua satisfação perante um espaço arquitetónico simulado;

3. Avaliar o uso deste sistema de simulação em projeto de arquitetura comercial.

Pretende-se assim estudar a satisfação dos utilizadores em relação a novas propostas para um determinado espaço, considerando as suas características arquitetónicas dentro da RVI, ambiente, luz, formas e cor, percebendo desta forma como reagem perante o mesmo. Ao longo do trabalho, e em parceira com a GALP, é também um ponto importante a avaliação do impacto da futura loja na motivação de consumo por parte do utilizador.

\section{Estado da Arte}

\section{Lojas de conveniência}

No nosso dia-a-dia, e derivado dos novos modos de vida que imprimem em muitos de nós uma constante atividade, é recorrente utilizar modos práticos e rápidos de obter bens sejam eles de que natureza forem. Neste contexto surge o comércio online e, no que respeita ao espaço físico, também as lojas de conveniência. Como o próprio nome indica as lojas de conveniência são lojas de venda de produtos de necessidade básica, não concorrendo com as grandes superfícies como os supermercados, mas sim destinando-se a compras de última instância. Estas lojas apresentam a rapidez e disponibilidade que o utilizador precisa, situam-se geralmente em localizações privilegiadas, sempre relativamente próximos de zonas residências, de locais muito movimentados, ou aliadas a outros serviços, como as estações de serviço. "Millennials, in, particular, value convenience in urban areas. Retailers across all channels are now competing on convenience, making the environment tougher for players in the traditional convenience/forecourt retail channels". (MALISON, 2016)

Tal como anteriormente referido, o trabalho realizado foi feito em parceria com a Galp com o objetivo de analisar a receptividade dos seus utilizadores relativamente a novos conceitos, dinamizando as suas lojas com o intuito de melhorar as vendas e proporcionar um melhor serviço aos utilizadores. Neste trabalho o alvo são as lojas de conveniência da Galp (Lojas Tangerina). De entre estas a tipologia estudada foi a de lojas Metropolitanas, aquelas que existem dentro das cidades e são utilizadas para, além do pagamento do combustível, adquirir tabaco, café, produtos básicos assim como o pequeno almoço. 
No seu estado atual as lojas Tangerina caracterizam-se na sua grande generalidade por lojas essencialmente ocupadas com prateleiras destinadas a jornais e revistas, produtos básicos e um pequeno espaço de refeição, pouco mais que duas a três mesas. Pelo facto destas lojas estarem aliadas a estações de combustível que têm normas restritas para a sua localização, quase todas elas têm grandes barreiras físicas em redor, tais como estradas de grande envergadura e avenidas com grande tráfego. Esta localização não favorece a sua integração urbana tornando-as locais isolados e dificultando que as lojas se tornem visíveis e acessíveis na óptica de utilizadores que se deslocam a pé.

\section{Novos conceitos de lojas}

Este trabalho foi desenvolvido em parceria com o grupo de investigação Marketing FutureCast Lab do AUDAX, Iscte. A análise de novos conceitos para lojas focou-se essencialmente no trabalho desenvolvido por alunos de mestrado de Marketing que analisaram o tema de aplicação de novos conceitos em lojas, nomeadamente o trabalho New Concepts In Convenience Stores de Sousa e Costa (2017).

Sousa e Costa (2017) fazem um Estado de Arte muito completo sobre o que se passa nesta área a nível internacional em termos de lojas e de conceitos específicos praticados. São apresentados pelos autores alguns exemplos bastante inovadores como lojas híbridas, que consistem essencialmente em dar uma outra razão para o consumidor voltar e/ou permanecer na loja oferecendo dois serviços diferentes no mesmo espaço, dando assim uma experiência nova ao utilizador. Sousa e Costa dão ainda alguns exemplos de outros países que já praticam estes conceitos, como na Tailândia em que algumas das empresas de lojas de conveniência oferecem mesas e cadeiras para os seus utilizadores puderem usufruir de uma refeição rápida e confortável.

Um segundo novo conceito que indicam é o de zonas com diferentes perceções. Nestas zonas é explorada a hipótese de se usar outros sentidos além do visual, explorando assim a luz do espaço a cor do mobiliário como estratégias de chamar a atenção do utilizador, criando diferentes espaços dentro da mesma loja de modo a atrair diferentes tipos de consumidores. Os autores referem ainda que ao se realizarem zonas diferenciadas, deve ser clara a diferença entre os locais de consumo (mesas de refeição) e os locais onde se encontra a comida para venda. Como exemplo no Japão a empresa Family Mart recorreu ao uso de mobiliário de diferentes tipos com o objetivo de fazer com que os utilizadores se sentissem mais em casa, dando também uma atmosfera de lounge, introduzindo ainda estações nas quais os utilizadores pudessem carregar os seus smartphones. 
Em terceiro surge o conceito digital com os ecrãs táteis e informativos nos quais é possível consultar e.g o inventário da loja, promoções, fazer compras 24 horas por dia e fazer publicidade a novos produtos (WHISBI, n.d.).

A utilização de meios digitais traz uma nova experiência ao utilizador rica em informação adicional. Alguns exemplos apresentados são a Coop em Itália na qual o utilizador pega num produto e são-lhe apresentados, num ecrã junto ao produto, os valores nutricionais do produto, desperdícios na sua conceção, como se de um rótulo melhorado se tratasse. Num outro exemplo uma aplicação desenvolvida pela Philips para o Smartphone permite que o consumidor tenha em tempo real a atualização do que existe em stock na loja.

O quarto conceito consiste na oferta aos utilizadores de experiências com o intuito de obter e manter a sua atenção, como o exemplo do Familymart e Walmart em que se introduz nos espaços destinados a refeições um comediante a realizar um espetáculo. De acordo com Gonsior e Brown (2016) "Entertainment introduces a social element that gives a center status as a destination. It gives people reasons to come and reasons to stay, presenting a new and different range of engaging activities and memorable experiences".

O quinto conceito assenta essencialmente sobre a adaptabilidade das lojas, características essa que permite diversificar as experiências dos seus utilizadores a cada visita que façam. Como referido por Sousa e Costa (201) no Mscafé na Polónia utilizam mobiliário móvel de modo a alterar regularmente a disposição do espaço.

Para além destes conceitos inovadores surge um outro, já praticado em vários países, que consiste na parceria entre lojas de conveniência e outras marcas. Em Portugal só em 2015 é que este conceito começou a ser explorado, através da BP e do Pingo Doce. No âmbito desta parceira o Pingo Doce explora uma parte do espaço das lojas da BP, com enfoque na oferta de bebidas com e sem álcool, comida congelada e fresca, jornais entre outros.

No que diz respeito a aspetos que devem ser meIhorados no futuro nas lojas Tangerina Sousa e Costa (2017) referem dois pontos fundamentais. O primeiro é a acessibilidade pedonal às lojas devido ao facto destas lojas serem também usadas por utilizadores que thes acedem a pé. O segundo diz respeito a uma maior visibilidade dos produtos.

\section{Realidade Virtual Imersiva}

A Realidade Virtual (RV) é uma tecnologia que permite uma interação entre o usuário e o sistema, com recurso a ferramentas exteriores, que pretende recriar ao máximo as sensações do mundo exterior (real), de tal modo que leva o usuário a percecionar esse espaço como a sua realidade. Para quem está 
a experimentar um ambiente virtual deve ser possível interagir com o ambiente $3 \mathrm{D}$ artificial e estar dentro da experiência simulada, sendo ela mais real ou menos real consoante vários fatores que iremos referir nesta secção. Dentro desta experiência podemos fazer uso de vários sentidos básicos do ser humano como visão e audição e em alguns casos o tato e o olfato.

A Realidade Virtual é frequentemente utilizada para testar soluções de projeto antes de estas serem construídas usando técnicas associadas às utilizados nos jogos de computador. Existem várias ferramentas para a visualização sendo as mais comuns, e devida a facilidade de transporte, os HMD. Estes constituem um pequeno dispositivo colocado na frente dos olhos do utilizador onde dois visores óticos projetam imagens estereoscópicas exclusivas a cada olho do utilizador e, ao fazê-lo, simula um ambiente 3D e a sensação de imersão corporal no espaço. Outro modo de observar o ambiente virtual são os ecrãs ou chamadas janelas para o ambiente virtual que são projeções e.g. num único ecrã (Powerwall) ou em vários écrans (CAVE). Nestas a informação digital é projetada de uma maneira a que o utilizador, ou utilizadores, são rodeados pelo ambiente projetado. Para a visualização dos conteúdos projetados em 3D são necessários óculos estereoscópicos e para interagir com o ambiente são necessárias ferramentas intermédios que vão desde os convencionais rato e teclado, até as câmaras que permitem localizar o individuo no espaço e sensores em luvas ou fatos de modo a ter uma leitura sobre a posição em tempo real do utilizador.

Dependendo do grau de imersividade do utilizador nestes ambientes virtuais obtemos experiências mais imersivas p.e. CAVE ou nos HMD e parcialmente imersivas p.e. nas Powerwall. (ELOY et al, 2018).

Quando se pretendem simular ambientes reais em Realidade Virtual de modo a obter respostas por parte dos utilizadores torna-se extremamente relevante a qualidade destes ambientes. Nas experiências realizadas em RVI a grande preocupação sempre foi o sentido de presença que o sujeito que está imerso tem. Estas questões estão bem presentes nos trabalhos de Slater et al (1994) e de SanchezVives e Slater (2005). Para Sanchez-Vives e Slater imersão é a descrição da fidelidade em relação ao real, dada pelos dispositivos e sistemas de interação.

De facto, é importante que o sujeito se sinta dentro do ambiente virtual para ser possível obter respostas claras e objetivas. Mas como consideramos mais ou menos válidos os ambientes de RV? Existem vários fatores que controlam a qualidade das experiências em RV e nos ambientes Imersivos. O primeiro aspeto é o campo de visão do sujeito que irá influenciar a sua experiência dependendo tam- 
bém do dispositivo utilizado para a visualização do ambiente virtual. O segundo aspeto é a frame-rate da imagem que o utilizador visualiza. Importante para a qualidade destes testes, visto ser através da fluidez e continuidade da imagem que é dada a noção da ilusão do ambiente virtual assemelhar-se mais ao real. $O$ terceiro aspeto bastante importante é a latência, ou seja, o tempo que o programa demora a responder após dado início à experiência, que por si está associada ao frame-rate e aos dispositivos de localização dos movimentos do sujeito. O quarto aspeto importante é a fidelidade visual com o mundo real que cada vez mais pode ser mais fiel devido também ao avanço da capacidade de processamento dos computadores, permitindo que se consiga produzir um ambiente virtual muito semelhante ao mundo real. Elementos como texturas e um certo realismo visual em relação à realidade, luz e sombras mais dinâmicas que dão mais sentido ao espaço, são características que permitem essa observação.

Apesar destes pontos em cima referidos serem essencialmente dependentes da capacidade da máquina que temos ao nosso dispor existem ainda outros que não são dependentes do poder da mesma. Estes são p.e. a presença de som/áudio que adiciona à experiência outros estímulos do mundo real. Obviamente que e.g num ambiente de loja, onde podemos ouvir outras pessoas a falar ou sons de outra natureza, ou no exterior onde se pode ouvir crianças a brincar e pássaros, vamos ter uma experiência muito mais rica do que se houvesse apenas silêncio em redor do sujeito. Todos estes aspetos em conjunto dão a sensação de imersão no ambiente virtual que, dependendo da qualidade de cada um destes fatores, irá tornar a experiência mais ou menos imersiva.

Como refere Sanchez-Vives e Slater (2005) se os ambientes virtuais imersivos fossem capazes de gerar a ilusão perfeita de estar e atuar no mundo virtual então provavelmente o problema da "presença" nunca teria surgido. Mas o que é a presença em ambientes virtuais? Apesar de estar relacionado com a imersão, a presença relaciona-se com as ações do sujeito dentro do ambiente, o seu comportamento propriamente dito, o facto de se sentir que está dentro de um espaço que de algum modo é real, o "Estar Lá". Digamos um cenário em que o sujeito no Ambiente Virtual está a percorrer um espaço no qual aparece uma passagem baixa entre dois volumes na qual ele sente que terá de andar abaixado. Aí o sujeito terá a tendência de se virar para passar de lado ou de se baixar de modo a não chocar nos volumes mesmo sabendo que estes objetos que se encontram perante ele, ou seja, não estão lá fisicamente. Apesar de não estarem o sujeito reage de um modo semelhante ao que reagiria no mundo real. Esta reação instintiva revela que há um sentido de presença dentro daquele ambiente virtual. Se o ambiente virtual for fiel o suficiente existirá sempre na consciência do sujeito a necessidade de reagir ao que the surge à frente de modo seme- 
Ihante ao que reagiria no mundo real.

Adicionalmente, em RVI podemos ter no mundo virtual um corpo virtual semelhante ao do sujeito um avatar - o que permite dar mais sentido de "estar lá". Em muitas experiências realizadas concluiuse que ao garantir que quando o individuo se movimenta o corpo virtual o acompanha, como por exemplo mexer o braço direito no mundo real e no ambiente virtual ele mexer também, há mais presença e é maior a sensação de estar presente no ambiente virtual. Hoje em dia já se encontram disponíveis fatos que fazem a leitura dos movimentos do corpo através de vários sensores e reproduzem esses no avatar, algo que é bastante usado na indústria dos filmes. Também luvas e fatos hápticos permitem que o utilizador sinta no seu corpo alguns estímulos que acontecem no mundo virtual

Mas como se pode avaliar a presença? O método mais usual de realizar essa avaliação é durante uma experiência de navegação em RVI. Testes conhecidos são o SUS (SLATER et al, 1994) e o W\&S (WITMER; SINGER, 1998). Estes utilizam um método de avaliação baseado numa série de perguntas que são colocados aos participantes e que seguem escalas de Likert entre os valores um (não sentir presente) até sete (muito presente).

\section{Uso de realidade virtual imersiva em estudos}

As leis da física do mundo real não existem de igual modo no mundo virtual (BOYTSHEFF;
SFEIR, 2007). Como tal, as possibilidades de criar espaços virtuais são imensas, bem como as possibilidades de experimentação dos espaços e elementos em termos arquitetónicos. Contudo é necessário ter presente que a RVI é uma ferramenta complementar e não um substituto da própria realidade (BOYTSHEFF et al., 2005).

Na medida em que RVI permite mostrar o espaço arquitetónico ainda inexistente, permitindo que este possa ser visto, avaliado e alterado antes da construção, esta apresenta grandes vantagens em termos de redução de custos decorrentes de erros ou más opções de projeto. A maior parte dos estudos sobre RVI têm-se debruçado sobre o impacto dos espaços arquitetónicos nos seus utilizadores, estudando a sua perceção, estado emocional, empatia e ligação enquanto experimentam o espaço (SCHNABEL; KVAN 2003; MAGHELAL et al, 2011; DIAS et al 2014a, 2014b)

Existem já várias experiências sobre este tema relativamente a espaços arquitetónicos, um dos bons exemplos é o de Boytsheff e Sfeir (2007). Nesse estudo são testados três espaços diferentes de modo a perceber as mais valias da realidade virtual no processo de criação. Nesta experiência o primeiro espaço testado tinha muitas semelhanças ao mundo real, o segundo era completamente sintético e imaginativo e o terceiro era uma mistura entre ambos. Foi analisado o nível de aceitação dos sujeitos sobre os espaços utilizados através de questionári- 
os, observações sobre os mesmos e recolha de dados biométricos que neste caso foi a temperatura da pele. A pergunta de investigação era se relacionada com a hipótese de haver uma mudança significativa ao experienciar os três espaços diferentes. Pediu-se aos sujeitos que se movessem livremente pelo espaço, de modo a compreender o impacto que poderia ter neles, percebendo também se o fato de ser longe do real os afetaria, e como.

Outros exemplos são o trabalho de Dias et al. (2014a, 2014b), que assentam sobre princípios de poder melhorar o espaço arquitetônico projetado realizando testes que demonstrem as respostas emocionais dos utilizadores perante determinados tipos de espaço. Foram realizados testes com recurso a questionários e sensores biométricos de modo a analisar as reações dos utilizadores e as possíveis emoções que os utilizadores estavam a experimentar.

À semelhança do uso em arquitetura, a RVI também tem sido bastante explorada em estudos sobre espaços comerciais possibilitando uma mais rica abordagem de Marketing, pretendendo ir mais ao encontro do que o utilizador precisa. A compreensão do comportamento dos consumidores é de grande importância para chegar a um eficaz marketing das lojas. A RVI permite que sejam feitos estudos de comportamento dos consumidores de modo a conseguir, não só prever o que estes desejam, mas também explorar novas maneiras de surpreender e agradar os utilizadores (LOUREIRO et al., 2019). A tecnologia da loja virtual, que consiste em desenvolver um modelo tridimensional de uma loja especialmente criada para se realizar os estudos sobre o comportamento dos utilizadores, foi introduzida nos negócios e em estudos para servir vários propósitos. Estes modelos podem ser utilizados como assistentes de inventário, ajudar as empresas a desenvolver um novo plano de organização dos produtos nas prateleiras bem como antever resultados das suas ações. Um uso mais comum das lojas virtuais é na investigação para avaliar o comportamento dos consumidores nas lojas e também em relação a mudanças nas lojas quer de ambiente, de preço, diferentes disposições de mobiliário, diferentes opções de embalagens e diferentes informações nutricionais nos rótulos das embalagens. As lojas virtuais são ainda atualmente usadas para criar e testar a saúde pública e para estimular escolhas mais saudáveis junto das crianças (PLOYDANAI et al. 2017).

Vários autores têm realizado testes em RVI e mesmo realidade aumentada para obter informações úteis sob o ponto de vista do Marketing, entre eles Krasonikolakis et al. (2014), Manis \& Choi (2019), Moralioglu (2018), Flavián et al. (2019) 
Ploydanai et al. (2017) realizaram testes utilizando a realidade virtual, nos quais se simularam várias lojas com diferentes tipologias. Neste trabalho foram testadas diferentes situações de lojas, tendo como base a hipótese de que diferentes disposições do mobiliário afetam o consumo e o tempo despendido numa loja. Alguns dos parâmetros considerados foram o tempo utilizado na loja, o espaço percorrido, os produtos examinados e os comprados. Durante a experiência foram divididos os utilizadores de igual modo por uma de quatro lojas e sem conhecimento das restantes de modo a garantir que não eram influenciadas por outra composição de mobiliário. Durante a experiência foi observado o comportamento de cada utilizador, recoIhendo os dados e analisando padrões, de modo perceber os padrões de comportamento. Este estudo concluiu que diferentes tipologias afetam de modo diferente o modo como as lojas são utilizadas e mesmo o volume de vendas que nelas é realizado. Este é um caso que comprova o interesse em desenvolver estudos de comportamento com base em RVI quando se projetam novas lojas.

\section{Projeto de uma loja \\ Programa de projeto}

Esta seção do trabalho refere-se ao projeto de arquitetura desenvolvido para uma loja de conveniência metropolitana Galp situada no Areeiro, em Lisboa no cruzamento da Avenida Gago Coutinho com a Avenida Marechal António de Spínola.
A loja caracteriza-se por ter uma grande afluência de utilizadores, normalmente que acedem de automóvel, sendo que os períodos de maior afluência são durante a manhã, horas de almoço e finais de tarde. Não existe permanência na loja por parte dos utilizadores, sendo que estes a utilizam maioritariamente para visitas curtas nas quais pagam o combustível, compram tabaco e tomam café. A oferta da loja inclui uma pequena zona com mesas onde os utilizadores podem usufruir de refeições bem como de outros bens que são vendidos nas prateleiras da mesma (Figura 2). Existe ainda uma zona periférica apenas destinada a venda de jornais e de revistas e outra com oferta de bens alimentares. No centro da loja existe um grande conjunto de estantes com produtos e bancadas promocionais com marcas especificas que preenchem o restante espaço. O espaço da loja é bastante grande, mas o centro encontra-se muito preenchido com as bancadas promocionais e mesmo mobiliário que dificulta a circulação e, pela falta de flexibilidade, impossibilita diferentes usos do espaço (Figura 1).

Sousa e Costa (2017) no seu trabalho focaram-se nas Lojas Tangerina da GALP e delinearam conceitos que podem fazer com que estas lojas sejam mais do que um ponto de venda de combustível e tabaco, mas também um ponto de recolha de alimentos, de lazer e de refeição com maior sucesso perante os utilizadores. Os novos conceitos apresentados e explorados por estes autores dividem-se em nove tipos: i) diversidade de produtos; ii) cantos/ 


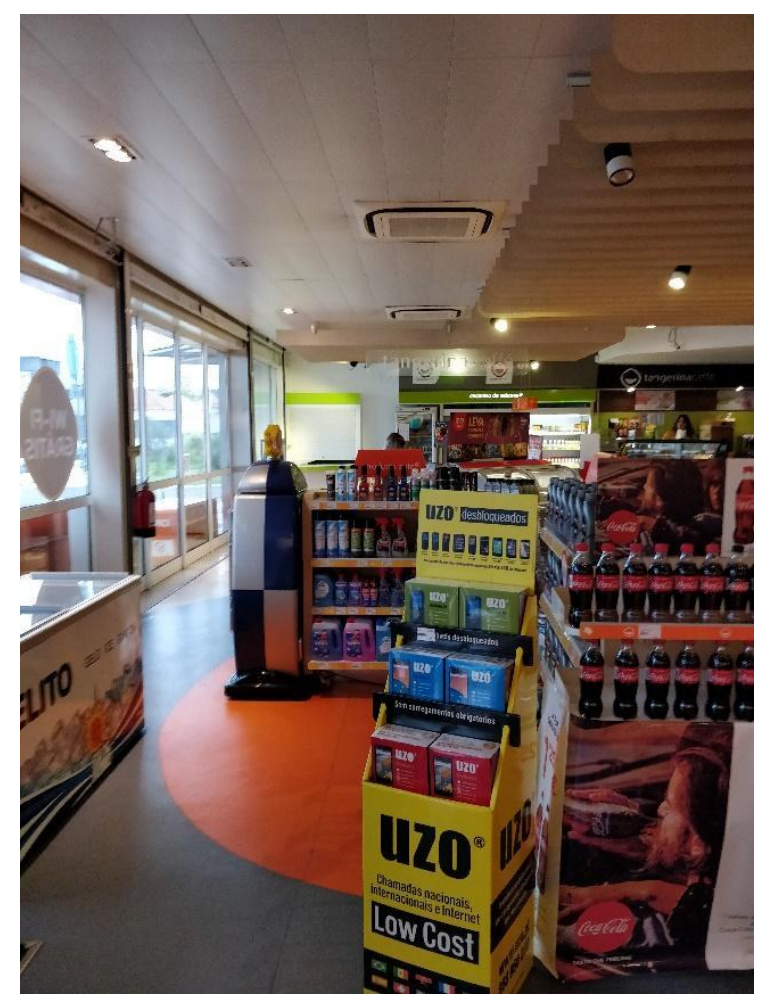

Figura 1 - Loja Tangerina Gago Coutinho - interior

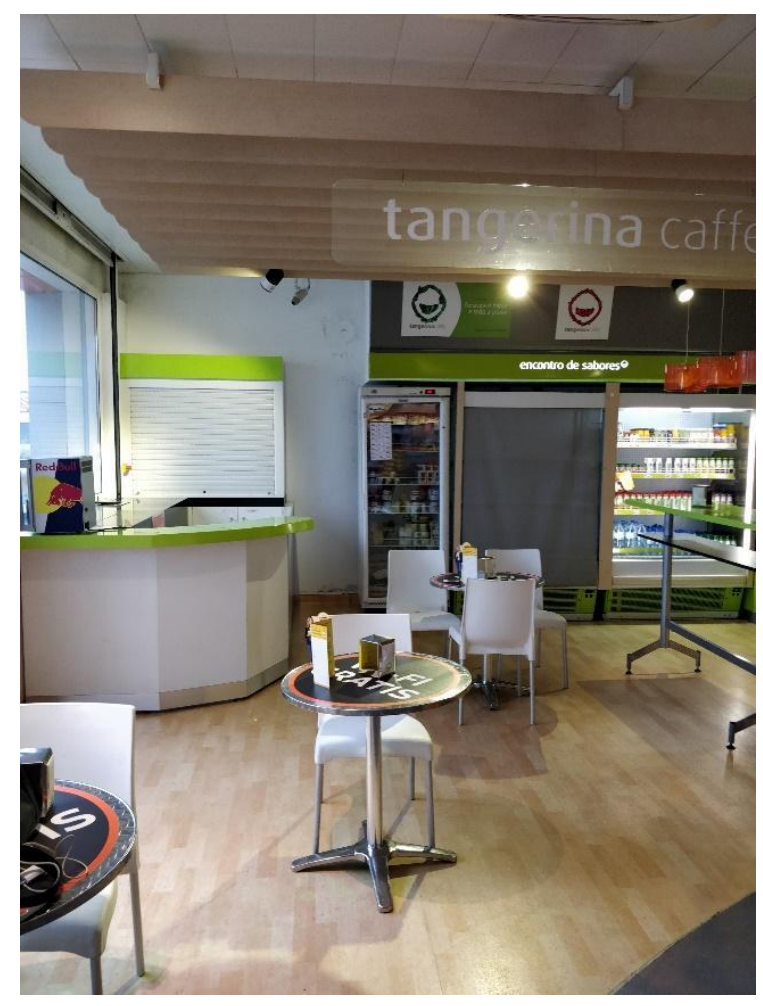

Figura 2 - Loja Tangerina Gago Coutinho - interior, zona de refeições

experiências nas lojas; iii) parcerias para zona de café; iv) zona de crianças; v) serviços diversos; vi) realidade virtual: vii) pontos de recolha; viii) acesso de pedestres; ix) e aplicações e tecnologia.

A maioria destes conceitos requerem maior flexibilidade no layout da loja. E.g. no sexto conceito em que é proposta a introdução da Realidade Virtual, esta pode ser temporária e no âmbito de promoção e.g. de imobiliária e automóvel. Uma introdução desta natureza permite experiências como testar um automóvel dentro de um simulador, percebendo o seu interior e a sua espacialidade, ou testar um apartamento, percebendo o espaço do imóvel, os seus acabamentos, as ligações entre compartimentos. Estas experiências têm o benefício não só de informar o utilizador, mas também induzir a compra. No seguimento deste trabalho o problema colocado pela GALP no que concerne à loja Tangerina em estudo foi o de falta de flexibilidade da loja para albergar produtos mutáveis ao longo das semanas e meses, promoções e eventuais exposições de produtos específicos.

\section{Metodologia}

Todo o processo de desenvolvimento do projeto foi efetuado segundo a seguinte metodologia que de desenvolveu em oito etapas.

Primeiramente foi realizada uma reunião com a Galp, onde foram definidos e discutidos aspetos considerados pelo cliente como forma de melhorar o ambiente da loja em termos de consumo e apresentação dos produtos. Nessa reunião foi traçado um rumo de trabalho que permitisse um bom diálogo entre o cliente e o investigador. Numa segunda etapa foi realizado o trabalho de investigação sobre o problema em estudo, culminando num estudo prévio da proposta com base em conceitos a explorar no projeto. Na terceira etapa foi realizada uma nova reunião com o cliente na qual se mostrou o resultado 
do trabalho efetuado até ali. Nesta reunião as soluções apresentadas foram discutidas e o cliente sugeriu algumas alterações com relevância para o impacto financeiro das soluções apresentadas. Foi nesta reunião que o foco da intervenção ficou totalmente definido. Nesse sentido, chegou-se à conclusão de que a intervenção se deveria focar na resolução do problema de falta de versatilidade do espaço, permitindo a mobilidade dos seus elementos mantendo simultaneamente a variedade de produtos já existentes e dinamizando o espaço da loja o máximo possível.

Numa quarta etapa voltou-se à conceção do projeto e reavaliou-se as soluções existentes mediante a discussão realizada na reunião com o cliente. Em seguida o trabalho realizado foi exposto novamente à Galp para obter o seu parecer. O projeto foi apresentado enquanto processo criativo e foi ainda feita uma demonstração das soluções em Realidade Virtual não imersiva (em ecrã visto o cliente estar representado por diversas pessoas) com vista a esclarecer quaisquer dúvidas, visualizando melhor o projeto. Nesta quinta etapa o parecer do cliente foi positivo e traçaram-se as etapas seguintes, nomeadamente como realizar os testes com os utilizadores das lojas Tangerina (etapa seis). Na sétima etapa os dados obtidos nos testes foram analisados pelo investigador. A última etapa do trabalho foi a realização de uma última reunião com a Galp onde se apresentaram os resultados do estudo.

\section{Conceção do projeto}

O processo de criação num projeto de arquitetura passa sempre pela procura de soluções que melhorem o existente. No que diz respeito ao programa arquitetónico este seguiu quer os interesses expressos pela GALP, quer, por se tratar de um trabalho académico, as indicações sobre novas tendências para lojas e a procura de resposta às questões de investigação lançadas no início do trabalho.

Tal como já foi referido, o projeto pretendia transformar o espaço existente conferindo-lhe maior versatilidade através da possibilidade de este ser modificado facilmente, assumindo diversas formas e funcionalidades. A solução encontrada assenta sobre um mobiliário que possa ser movimentado dentro do espaço por meio de um circuito de calhas instaladas no teto da loja e tenha rodas na parte inferior para assim conseguir deslizar facilmente. Este sistema permite movimentar o mobiliário num circuito fechado que seria alterado semanalmente ou quinzenalmente para criar diferentes disposições e sensações no espaço, possibilitar a existência de cantos ou zonas de promoção de novos produtos assim como deixar o espaço totalmente livre se necessário. Este mobiliário permite ainda o posicionamento de écrans táteis que permitem efetuar pagamentos e obter informações referentes a promoções.

Realizaram-se duas propostas de mobiliário, a $\mathrm{A}$ e a $B$ (Figura 3 a Figura 6). A primeira solução, A, con- 


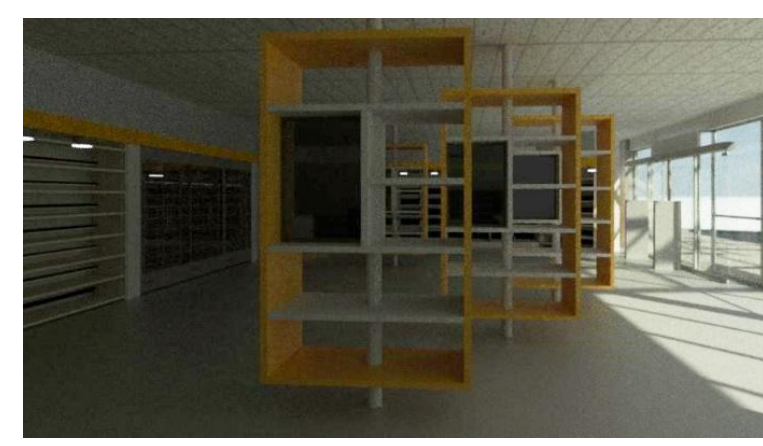

Figura 3 - Proposta de mobiliário A com uma das várias disposições possíveis

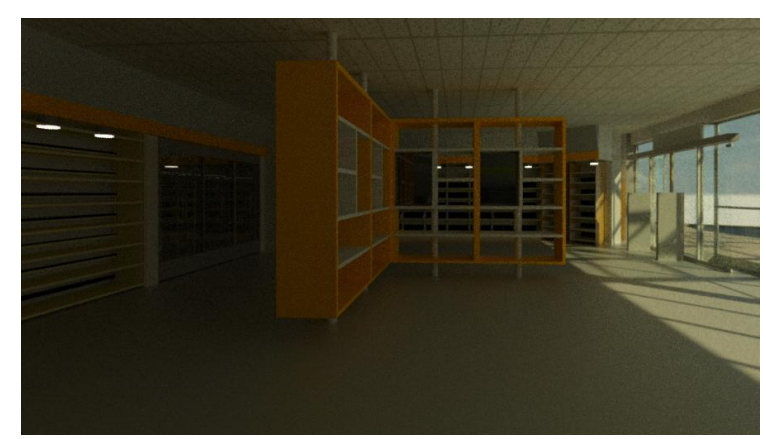

Figura 4 - Proposta de mobiliário A com outra das várias disposições possíveis

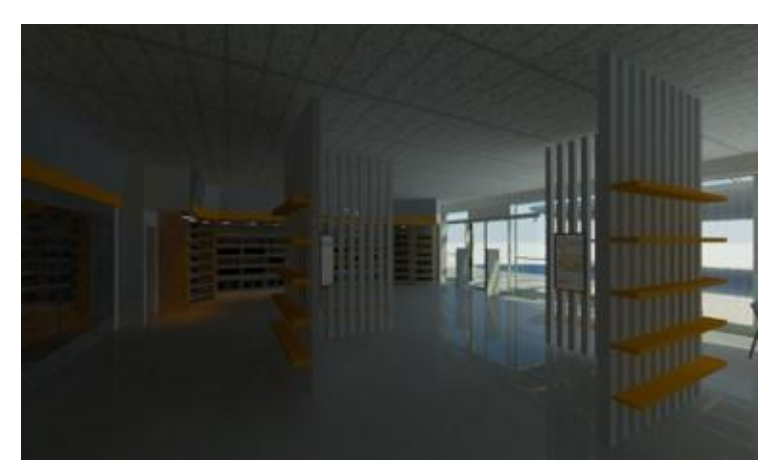

Figura 5 - Proposta de mobiliário B com uma das várias disposições possíveis

usjt • arq.urb • número 28 | maio-agosto de 2020

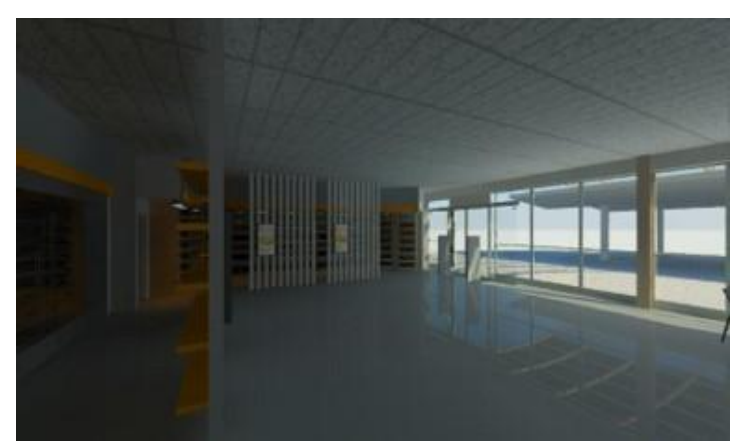

siste num volume retangular que assenta no topo e parte inferior num elemento vertical, ligado ao teto e ao pavimento. $\mathrm{O}$ mobiliário tem $1.80 \mathrm{~m}$ de altura e é dividido em quatro zonas de prateleiras vazadas com 0,60 $\mathrm{m}$ de profundidade para colocar os produtos expostos, bem como écran(s) tátil(eis). 0

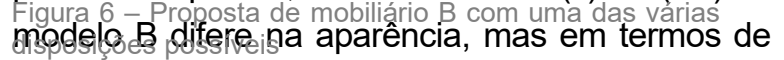
mobilidade e diversificação do espaço tem os mesmos princípios. Este mobiliário $B$ constitui um conjunto de ripas verticais com secção quadrada de $0,10 \mathrm{~m}$, e com espaçamento entre elas de $0,10 \mathrm{~m}$ e que se repetem por 1,60 m de comprimento. Nestas ripas assentam quatro prateleiras que encaixam nas ripas através de peças que são inseridas ao longo do seu comprimento. Na parte posterior das ripas está localizado um ecrã tátil com as funções já referidas.

\section{Análise da satisfação dos utilizadores utilizan- do a Realidade Virtual Imersiva}

De modo a avaliar a satisfação dos utilizadores perante as possibilidades de alteração do layout da loja Tangerina desenhou-se uma experiência em RVI que pressupunha a participação de diversos utilizadores aos quais seriam apresentadas as propostas de alteração. Nesta secção faz-se a descrição de todo o processo de realização da experiência desde o seu desenho até à sua concretização. A realização da experiência pressupõe a definição primeiramente de um protocolo de experimentação no qual se define como que um guião sobre todos os passos necessários para realizar a experiência. É ainda necessário definir o aparato experimental que inclui o software e hardware utilizado assim como os critérios para escolha dos participantes.

As experiências foram realizadas na Loja Galp Tangerina localizada em Lisboa, Areeiro na Avenida Gago Coutinho nos dias 5 e 6 de setembro de 2018. $\mathrm{Na}$ realização das experiências estiveram envolvidos em simultâneo dois investigadores.

\section{Protocolo de experimentação}

A realização do protocolo de experimentação foi sempre acompanhada pela Galp desde o início até ao final. A principal solicitação da Galp relativa ao momento da realização das experiências foi a de 
abordar as pessoas apenas depois de efetuarem o pagamento na loja.

A realização das experiências incluiu as seguintes quatro fases.

\section{FASE 1}

Um investigador aborda os utilizadores à saída da loja e pergunta se têm disponibilidade para fazer parte de um estudo de modo voluntário.

\section{FASE 2}

Um investigador apresenta ao participante as perguntas em forma de questionário de modo a recoIher informação prévia à experiência. Este $1^{\circ}$ questionário inclui perguntas relativas a três grupos: i) caraterização do participante (1 pergunta); ii) experiência prévia do participante na loja (6 perguntas) iii) experiência do participante com ambientes virtuais (2 perguntas).

\section{FASE 3}

O mesmo investigador explica ao participante que este vai visualizar dois projetos em RVI e explica que são propostas para o futuro da loja onde se situam. O investigador coloca ou ajuda a colocar um HMD (Oculus Rift) no participante e explica como este se pode movimentar no modelo utilizando o rato e o teclado do computador. O participante é informado que pode navegar livremente em toda a loja e demorar o tempo que quiser. Toda a experiência é observada pelo investigador pedindo ao participante para falar alto sobre o que está a pensar. Primeiramente é mostrado o projeto $\mathrm{A}$, com duas alternativas de disposição do mobiliário, e depois 0 projeto $B$, também com duas alternativas de disposição do mobiliário. Para o participante seguinte a ordem de apresentação é invertida em relação ao participante anterior de modo a evitar um enviesamento nas respostas.

\section{FASE 4}

O segundo investigador pede ao participante que responda ao $2^{\circ}$ e $3^{\circ}$ questionários. Estes questionários são iguais, mas o $2^{\circ}$ corresponde ao modelo $A$ e $\circ 3^{\circ}$ ao modelo $B$. As perguntas incluídas neste questionário referem-se a: i) sensação de presença no espaço (10 perguntas); ii) perceção geral do espaço (3 perguntas); iii) perceção específica do espaço relativo ao modelo A e B (4 perguntas fechadas e 2 perguntas abertas para cada modelo).

\section{Aparato experimental}

Para a realização da experiência foi utilizado um computador portátil MSI GT72VR, que reunia o software necessário ao processamento gráfico do modelo, e o conjunto de material dos Oculus Rift (HDM e sensores de tracking) para a visualização 


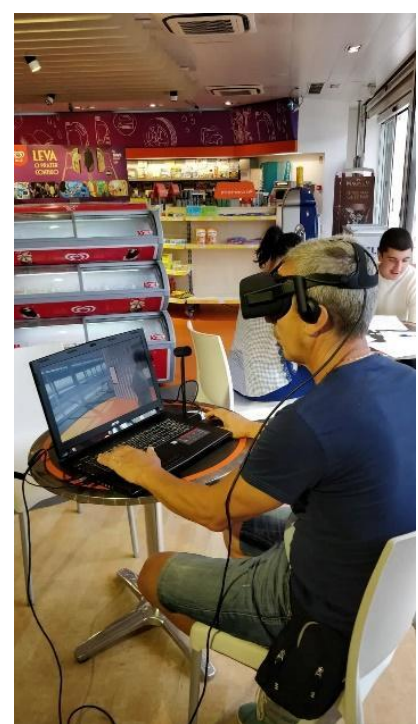

Figura 7 (esquerda) - Participantes a realizar a experiência

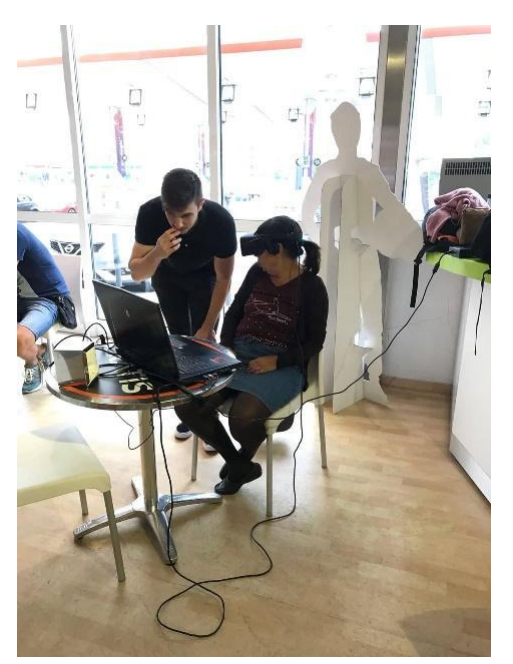

Figura 8 (direita) - Participantes a realizar a experiência

usjt • arq.urb • número 28 | maio-agosto de 2020 propriamente dita do modelo. A navegação foi feita tendo como interface o rato e o teclado de modo a permitir uma aprendizagem mais rápida aos participantes.

O modelo tridimensional do espaço foi realizado em software BIM (Autodesk Revit) que posteriormente foi exportado para Unity de modo a correr em realidade virtual. No Unity foram adicionados a iluminação e avatares de modo a conferir um ambiente mais próximo do real.

\section{Participantes}

Na realização da experiência participaram 12 utilizadores da loja Tangerina Galp. Os participantes que realizaram a experiência enquadram-se em faixas etárias compreendidas entre os 14 e os 69 anos, sendo cinco mulheres e sete homens.

\section{Resultados}

Posteriormente à realização das experiências, analisaram-se os resultados obtidos para encontrar respostas às três questões de investigação, colocadas no início do estudo.

Conforme indicado na secção 5.1, foram realizados três questionários cada um deles com uma série de questões. As respostas foram dadas utilizando uma escala de avaliação entre 1 e 7 em que 1 corresponde ao discordo totalmente com a afirmação e 7 corresponde ao concordo totalmente com a afirmação. É considerado como resultado positivo respostas acima de 4 e resultados negativos abaixo do mesmo.

Os resultados obtidos são descritos nesta secção.

Em relação ao primeiro questionário, relativamente aos hábitos dos participantes no que respeita ao uso da loja Tangerina, os resultados dizem que a maioria das pessoas utiliza a loja quer para abastecer quer para realizar compras (média 4.4, desvio padrão 2.0) e a frequência de uso é baixa (média 3.1, desvio padrão 1.8). No que diz respeito aos resultados caracterizadores da experiência prévia dos participantes em ambientes virtuais, cerca de $33 \%$ revelaram terem tido já outras experiências em Realidade Virtual e os restantes $77 \%$ tem pouca ou nenhuma relação com ambientes virtuais. Cerca de $25 \%$ dos participantes revelou alguma prática com jogos de computador.

Os participantes consideram que a disposição atual da loja Tangerina é boa (média 5.0, desvio padrão 1.6) e que a atual disposição dos expositores valoriza em certa medida a compra de produtos (média 4.5, desvio padrão 1.8). Quando questionados sobre se a atual disposição dos expositores valoriza outras ações que possam ser realizadas na loja e que não apenas a compra de produtos os partici- 


\begin{tabular}{|c|c|c|}
\hline Questionário presença SUS & Média & $\begin{array}{l}\text { Desvio } \\
\text { Padrão }\end{array}$ \\
\hline O quão real lhe pareceu o mundo virtual? & 6.3 & 0.6 \\
\hline $\begin{array}{l}\text { Até que ponto houve vezes em que sentiu que o mundo virtual passou a ser } \\
\text { "realidade" para si, e quase se esqueceu do mundo real lá fora? }\end{array}$ & 5.3 & 1.4 \\
\hline O mundo virtual pareceu mais como algo que viu, ou um lugar que visitou? & 5.4 & 1.7 \\
\hline Total & 5.7 & 1.3 \\
\hline \multicolumn{3}{|l|}{ Questionário presença W\&S } \\
\hline Em que medida conseguiu controlar os eventos? & 5 & 1.5 \\
\hline De que modo foi responsivo o ambiente às suas ações? & 4.9 & 1.7 \\
\hline Até que ponto foram envolventes os aspetos visuais do ambiente virtual? & 5.75 & 1 \\
\hline Foram naturais os mecanismos de navegação no mundo virtual (comandos)? & 5.75 & 1.7 \\
\hline $\begin{array}{l}\text { Até que ponto teve consciência da presença dos dispositivos de controlo } \\
\text { (comandos) durante a simulação? }\end{array}$ & 4.5 & 1.6 \\
\hline $\begin{array}{l}\text { Em que medida foi consistente a experiência no mundo virtual com as experiências } \\
\text { no mundo real? }\end{array}$ & 5.4 & 1 \\
\hline Com que velocidade se conseguiu adaptar à experiência de realidade virtual? & 5 & 1.3 \\
\hline Total & 5.2 & 1.5 \\
\hline
\end{tabular}

Figura 9 - Respostas aos questionários SUS e W\&S.

usjt • arq.urb • número 28 | maio-agosto de 2020 perceção do espaço e das alterações realizadas.
Tal como referido atrás, a sensação de presença é essencial para garantir que os participantes têm uma completa experiência do espaço que está simulado. Sendo assim, na primeira parte dos questionários dois e três pretendia-se compreender a presença dos participantes durante a experiência. Para tal foram utilizados parcialmente os questionários de presença de Slater, Usho \& Steed (1994) (SUS) e Witmer \& Singer (1998) (W\&S). A Figura 9 mostra os resultados da presença sendo que 1 equivale a presença baixa e 7 equivale a presença alta. Os resultados, quer para o questionário SUS quer para o questionário de W\&S mostram que o ambiente virtual deu ao participante um elevado sentido de presença, estando esta sempre acima do valor 4 e em média acima do valor 5 .

A segunda parte do questionário dois e três referese a perguntas relativas à perceção geral do espaço em RVI. Nas perguntas de caráter geral, os participantes reportaram que se sentiam agradados por serem consultados sobre as possíveis alterações à loja (média 5.1, desvio padrão 0.83). Foi também bastante do agrado dos participantes a possibilidade de passear livremente no modelo de realidade virtual imersiva para perceber alternativas de projeto para a loja (média 6.2, desvio padrão 0.75). Quando questionados sobre a periodicidade de alteração do layout da loja, os participantes responderam que preferiam uma mudança entre mensal e trimestral (média 2.4 , desvio padrão 0.79 , sendo que 1 para semanal, 2 para mensal e 3 para trimestral). 


\begin{tabular}{lccccc}
\hline & \multicolumn{2}{c}{ Modelo A } & \multicolumn{2}{c}{ Modelo B } \\
\cline { 2 - 6 } & Média $\begin{array}{c}\text { Desvio } \\
\text { Padrão }\end{array}$ & Média $\begin{array}{l}\text { Desvio } \\
\text { Padrão }\end{array}$ \\
\hline $\begin{array}{l}\text { A loja pareceu-lhe mais apelativa no modelo virtual do que no seu } \\
\text { estado atual? }\end{array}$ & 6 & 1.1 & 6.4 & 0.7 \\
\hline $\begin{array}{l}\text { A nova disposição do mobiliário favorece e torna mais apelativo o } \\
\text { consumo? }\end{array}$ & 5.6 & 1.1 & 6.3 & 0.6 \\
\hline $\begin{array}{l}\text { A nova disposição do mobiliário favorece uma utilização mais } \\
\text { flexivel da loja na qual é possível ter outras configurações e } \\
\text { apresentar diversos produtos? }\end{array}$ & 6.2 & 1.0 & 6.6 & 0.7 \\
\hline A nova disposição do mobiliário favorece o movimento na loja? & 6.7 & 0.6 & 6.3 & 0.6 \\
\hline
\end{tabular}

Figura 10 - Respostas às perguntas específicas sobre perceção do espaço do modelo A e B. Respostas na escala de 1 dis cordo totalmente e 7 concordo totalmente.

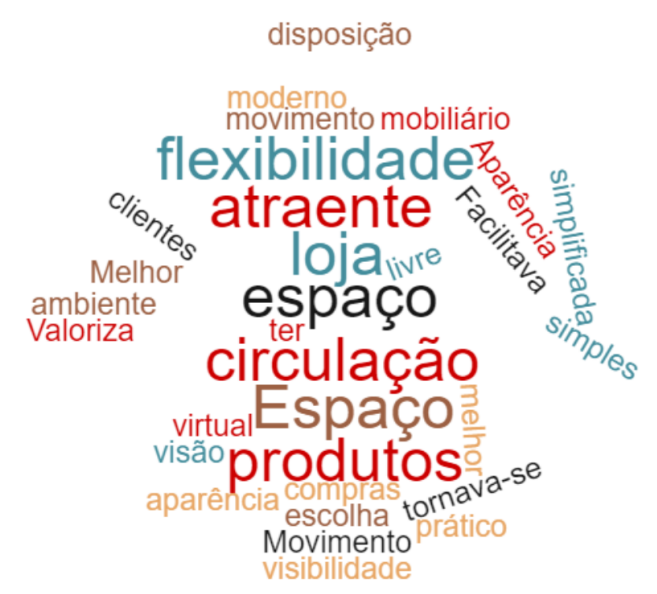

Figura 11 - Nuvem de palavras referente à primeira pergunta aberta do questionário do modelo $\mathrm{A}$

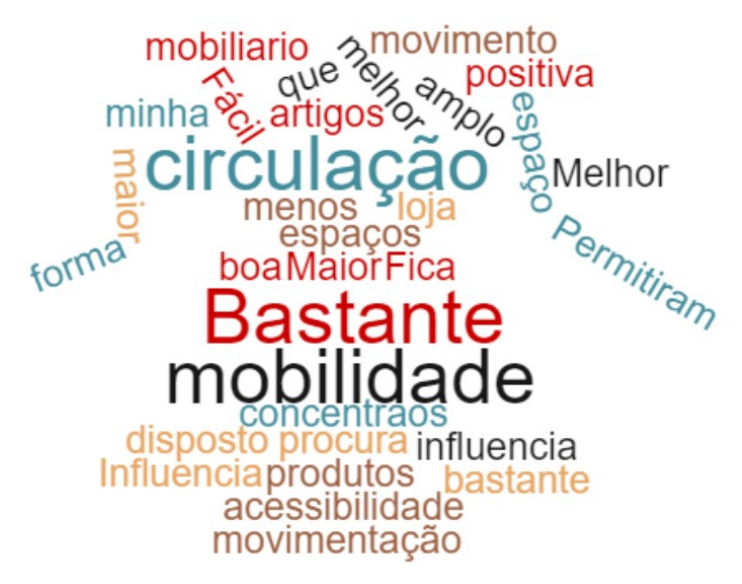

Figura 12 - Nuvem de palavras referente à primeira pergunta aberta do questionário do modelo $\mathrm{B}$
A terceira parte do questionário dois e três incluía questões relacionadas especificamente com o modelo A e o modelo $\mathrm{B}$.

$\mathrm{Na}$ sua generalidade a perceção dos utilizadores perante as alterações propostas foi boa. Como pode ser visto na Figura 10 a maioria dos inquiridos sentiu que ambas as propostas (modelos A e B) apresentadas no espaço virtual eram mais atrativas do que o espaço real atual. Com essas alterações a loja ficaria mais apelativa, favoreceria o movimento no espaço e permitiria uma utilização mais flexível do mobiliário.

Como se pode observar pelos resultados ambos os modelos tiveram uma aceitação muito positiva. Ainda assim, o modelo B, tanto por apresentar, na generalidade, médias superiores como pelos valores do desvio padrão, que mostram uma maior proximidade de respostas e consequentemente resultados que podem ser considerados mais válidos, teve um nível maior de aprovação.

Os comentários incluídos nas perguntas abertas foram muito diferenciados pelo que se optou por fazer uma análise através de nuvem de palavras de modo a obter as palavras mais utilizadas pelos participantes para responder a P1: "Que aspetos acha que o projeto valoriza em relação a loja atual?" e P2: “Em que medida os mobiliários dispostos no modelo influenciaram o seu movimento no espaço" (Figura 9 a Figura 12). 


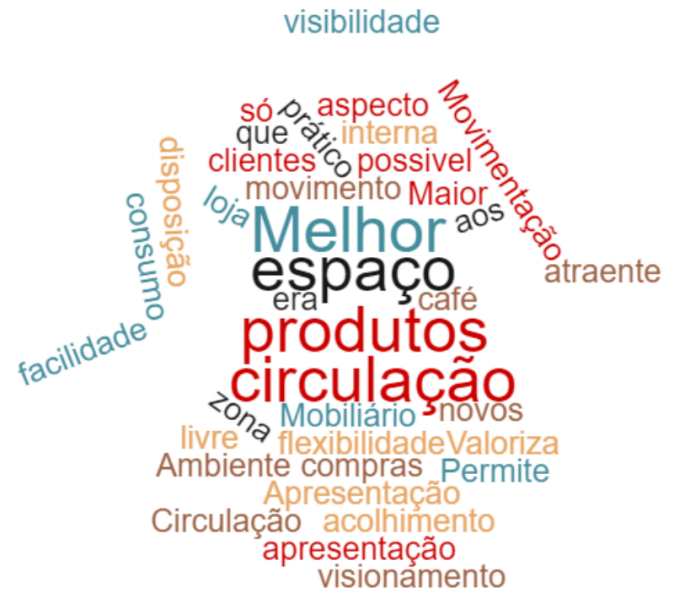

Figura 13 - Nuvem de palavras referente à primeira segunda aberta do questionário do modelo $\mathrm{A}$

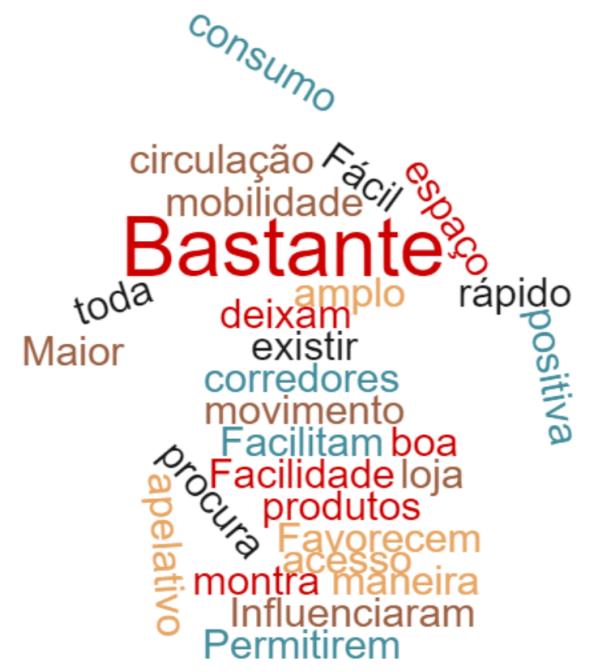

Figura 14 - Nuvem de palavras referente à primeira segunda aberta do questionário do modelo B

usjt • arq.urb • número 28 | maio-agosto de 2020
As respostas indicam que os aspetos mais valorizados de ambas as propostas em relação à loja atual são a flexibilidade, a circulação e o espaço para o modelo A e a circulação e a mobilidade para o modelo B. Para classificar em que medida o mobiliário influenciou o movimento no espaço os participantes usaram palavras para o descrever como, "Bastante" e "Melhor" o que mostra o sentido positivo que as propostas têm ao nível do movimento.

\section{Discussão e conclusões}

O presente trabalho debruça-se sobre a comunicação entre cliente, utilizadores do espaço e projetista e os modos como esta pode ser realizada de modo mais eficiente e compreensível para o cliente e utilizadores. A comunicação entre as partes envolvidas num processo de projeto de arquitetura muitas vezes comporta equívocos que só são clarificados após a obra e muito tardiamente para se realizarem alterações ao projeto.

A realidade virtual imersiva foi utilizada neste trabaIho como ferramenta de visualização para avaliar a sua utilidade no processo comunicação do projeto aos utilizadores finais analisando assim a satisfação destes em relação ao espaço arquitetónico simulado que thes é apresentado. $O$ estudo do espaço comercial em questão, loja Tangerina da Galp, teve a vantagem de permitir simultaneamente trabalhar diretamente com um cliente real com preo- cupações e problemas reais e utilizando metodologias científicas responder às perguntas de investigação.

Na realização do trabalho foi feita uma pesquisa que permitiu enquadrar os conhecimentos sobre a problemática de projeto em estudo, nomeadamente a arquitetura comercial e as tendências atuais. A realização de um projeto de arquitetura comercial serviu como caso de estudo para responder às perguntas de investigação colocadas, relativas ao papel da RVI na facilidade de compreensão dos projetos de arquitetura. Nesse sentido foi realizada uma experiência onde participantes, utilizadores reais da loja Tangerina, foram confrontados com alternativas de projeto simulado em realidade virtual. Os questionários realizados após estas experiências permitiram comparar não só a sua satisfação com a loja atual, mas também a sua satisfação relativa às propostas de alteração realizadas.

Os dados obtidos através da experiência indicam que quando questionados sobre a loja os utilizadores finais admitem que a sua disposição atual não valoriza a realização de quaisquer outras atividades. Como observamos no capítulo anterior os participantes consideraram que a atual disposição não permite que se possa p.e apresentar um produto novo na loja o que leva a uma utilização mais pobre da mesma. 
Apesar de não ser o foque do estudo, um aspeto interessante que surgiu das respostas foi a satisfação dos participantes perante o facto de estarem a ser consultados perante propostas futuras para o espaço. De facto, os participantes ficaram muito satisfeitos em relação à oportunidade de passear livremente no espaço virtual para assim conseguirem entender todo o projeto com o máximo de informação e detalhe que precisem. Este é um aspeto muito relevante em arquitetura e enfatiza a noção que o utilizador gosta de ser consultado ativamente e de poder visualizar e perceber o espaço que está a ser projetado e que irá frequentar no futuro.

Relativamente aos dois modelos desenhados para resolver os problemas encontrados na loja, ambos tiveram bastante aceitação, como se observa nos resultados. Quando questionados sobre a satisfação perante os modelos os resultados obtidos em todas as perguntas são positivos situando-se sempre acima do 6.0, à exceção de um caso cuja satisfação foi de 5.6. Os resultados indicam que uma atualização ao espaço é necessária e que a intervenção passa por modelos que possibilitem maior mobilidade, exposição de produtos e acima de tudo a capacidade de ter mais atividades a decorrer, ou seja, utilização mais flexível.

Como resultados finais do projeto podemos elencar a perceção da RVI como uma ferramenta que per- mite aos clientes e utilizadores do espaço arquitetónico (leigos em representação convencional de arquitetura) entenderem as propostas para o espaço, e ainda a satisfação que estes têm quando confrontados com este tipo de visualização natural e o facto de serem consultados sobre o futuro do espaço que habitam.

\section{Agradecimentos}

Os autores gostariam de manifestar o seu agradecimento à Galp nomeadamente a Luís Madeira Lopes, Patrícia Boavida, Joana Duarte, João Torneiro.

\section{Referências}

BOYTSCHEFF, C.; SFEIR, M. K. Experimental Results in immersive Virtual Reality (IVR): Searching Critical Design Factors within IVR to Increase Architectural Space Qualities. In: PREDICTING THE FUTURE, 25TH ECAADE CONFERENCE PROCEEDINGS, 2007, p. 91-98.

BOYTSCHEFF, C.; KANACRI SFEIR, M.; KLOTZEL, C.; BADEr, J.; FICHTER, D. Polarity in Virtual Constructions. Stuttgart: University of Stuttgart, 2005.

DIAS, M. S.; ELOY, S.; CARREIRO, M.; MARQUES, S.; MOURAL, A.: CRUZ, J.: PEDRO, T. Space Perception in Virtual Enviroments. On how 
biometric sensing in virtual environments may give architects user's feedback. In: FUSION PROCEEDINGS OF THE 32ND ECAADE CONFERENCE, 2014a, vol. 112, p. 1-10.

DIAS, M. S.; ELOY, S.; CARREIRO, M.; PROENÇA, P.; MOURAL, A.; PEDRO, T.; FREITAS, J.; VILAR, E.; ALPUIM; AZEVEDO; A. S. Designing better spaces for people. In: RETHINKING COMPREHENSIVE DESIGN: SPECULATIVE COUNTERCULTURE, PROCEEDINGS OF THE 19TH INTERNATIONAL CONFERENCE ON COMPUTER-AIDED ARCHITECTURAL DESIGN RESEARCH IN ASIA (CAADRIA 2014), Kyoto 1416 May, 2014b, p. 739-748

ELOY, S.; OURIQUE, L.; WOSSNER, U.; KIEFERLE, J.; SCHOTTE, W. How present am I: three virtual reality facilities testing the fear of falling. In: PROCEEDINGS OF THE 36TH ECAADE CONFERENCE - Volume 2, Lodz University of Technology, Lodz, Poland, 19-21 September 2018, p. 717-726

FLAVIÁN, C., IBÁÑEZ-SÁNCHEZ, S., \& ORÚS, C. The impact of virtual, augmented and mixed reality technologies on the customer experience. Journal of Business Research, v.100, July 2019, p.547560. https://doi.org/10.1016/j.jbusres.2018.10.050
GONSIOR, T.; BROWN, B. A fresh take on 'Retailtainment' and future of fun. 2016. Disponível em: $<$ https://www.chainstoreage.com/real-estate/freshtake-retailtainment-and-future-fun/>. Acesso em: 6 fev. 2019

MALISON, M. The New Definition of Convenience Retail. 2016. Disponível em: <https://blog.euromonitor.com/the-new-definition-of-convenience-retail/>. Acesso em: 6 fev. 2019

KRASONIKOLAKIS, I.; VRECHOPOULOS, A.; POULOUDI, A. Store selection criteria and sales prediction in virtual worlds. Information \& Management, v.51 (6), p. 641-652, 2014. https://doi.org/ 10.1016/j.im.2014.05.017

LOUREIRO, S. M. C.; GUERREIRO, J.; ELOY, S.; LANGARO, D.; PANCHAPAKESAN, P. Understanding the use of Virtual Reality in Marketing: A text mining-based review. Journal of Business Research, v.100, July 2019, p.514-530. https://doi.org/ 10.1016/j.jbusres.2018.10.055

MANIS, K. T.; CHOI, D. The virtual reality hardware acceptance model (VR-HAM): Extending and individuating the technology acceptance model (TAM) for virtual reality hardware. Journal of Business Research, v.100, July 2019, p.503-513. https://doi.org/ 10.1016/j.jbusres.2018.10.021 
MAGHELAL, P.; NATESAN, P.; NADERI, J. R.; KWEON, Byoung-Suk. Investigating the Use of Virtual Reality for Pedestrian Environments. Journal of Architectural and Planning Research, 28(2), Summer 2011, p.104-117.

MORALIOGLU, B. Spatial User Interfaces in Mixed Reality: Online Shopping Experience Design. In: COMPUTING FOR A BETTER TOMORROW PROCEEDINGS OF THE 36TH ECAADE CONFERENCE, vol.2, Lodz University of Technology, Lodz, Poland, 19-21 September 2018, p. 753760

PLOYDANAI, K.; PUTTLELAAR, J.V.D.; HERPEN, E.V.; TRUP, H.V. Using a virtual store as a research tool to investigate consumer in-store behavior. Journal of Visualized Experiments. Jul 24;(125), 2017. doi: $10.3791 / 55719$

SANCHEZ-VIVES, M. V.; SLATER, M. From presence to consciousness through virtual reality. Nature Reviews Neuroscience, 6(4), 2005. p.332339.

SCHNABEL, M.; KVAN, T. Spatial Understanding in Immersive Virtual Environments. International Journal of Architectural Computing, 1(4), 2003, p.435-448. https://doi.org/
SLATER, M.; USOH, M.; STEED, A. Depth of Presence in Immersive Virtual Environments. Presence: Teleoperators and Virtual Environments, 3(2), 1994, p. 130-144.

SOUSA, R.; P., COSTA, A. New Concepts in Convenience Stores. Lisboa: Instituto Universitário de Lisboa (ISCTE-IUL), 2007.

WITMER, B. G; SINGER, M. J. Measuring Presence in Virtual Environments: A Presence Questionnaire. Presence: Teleoperators and Virtual Environments, 7(3), 1998, p. 225-240. doi: 10.1162/105474698565686.

WHISBI. Interactive retail display is a new favorite in and out of store. N.d. Disponivel em: <https:// www.whisbi.com/info/omnichannel/solution/retail/instore/interactive.html>. Acesso em: 6 fev. 2019.

10.1260/147807703773633455 